APRJ, Issue 1 (2014), pp 34-49

\title{
How members of the public account for the England Riots of summer 2011
}

\author{
Authors: Simon Goodman, Shelley A. Price and Charlotte Venables
}

\begin{abstract}
The purpose of this study is to gain knowledge of how the general public viewed the England riots of 2011 in order to gain a fuller understanding of the riots and their impact on society. The study involved the thematic analysis of four semi-structured focus groups that were conducted with a total of eighteen participants from differing backgrounds. The analysis identified five themes which are: (1) participants draw on traditional theories of the crowd; (2) the Police were deemed to be 'damned if they do and damned if they don't'; (3) opportunism was used to account for looting; (4) the media were viewed as aiding the spread of the riots but also as informative and as aiding the cleanup after the riots ended; and (5) the riots were presented as being understandable, but in no way acceptable. This demonstrates how public understanding of the riots differs from the psychological literature. Practical recommendations are suggested including the need to give a platform to crowd psychologists.
\end{abstract}

Key words: Riot; England Riots; Public Understanding; ESIM; Thematic Analysis

\section{Introduction}

\section{Background and Context}

On Thursday 4th August 2011, Mark Duggan was killed by Police in Tottenham, a poor area of North London, England. On Saturday $6^{\text {th }}$ a protest took place about the shooting outside Tottenham Police station and this protest eventually turned violent and riots broke out that evening. The following night the riots spread across London and in a third day of violence the riots continued in London but also spread to the other major English cities of Bristol, Birmingham, and Nottingham. By the forth day of violence there was no longer rioting in London, but the riots continued throughout England, spreading to Manchester and Liverpool as well as their surrounding towns ${ }^{1}$. In total the riots went on for five days. As this was a long lasting and widespread event, it became the focus of much public and media attention both within the UK and internationally ${ }^{2}$. This paper sets out to investigate how members of the public talk about, and account for, these riots.

A wide range of explanations for the riots was discussed publicly throughout the media. These included (but were not limited to) focussing on what can be seen as 'cultural' issues including blaming 'youths' and youth culture $^{3}$, 'moral collapse' in the $\mathrm{UK}^{4}$, an 'X-Factor culture' ${ }^{5}$ and the lack of harsh discipline for young people ${ }^{6}$. The notion of opportunism, that is that rioters took the opportunity to loot for goods that they would like, but didn't want to pay for, was also widely discussed as part of the problem of a greedy culture. ${ }^{7}$ These

[Contact: Simon Goodman, Department of Psychology and Behavioural Sciences, Coventry University, Priory Street, Coventry, CV1 5FB; Email: Simon.Goodman@coventry.ac.uk; Shelley Price, Department of Psychology and Behavioural Sciences, Coventry University; Charlotte Venables, Department of Psychology and Behavioural 
explanations can be categorised as having a focus on the actions of individuals (albeit individuals influenced by the wider culture). Such explanations tended to come from those more to the right of the political spectrum. Arguably the most individualistic (and explicitly non-social) explanation came from the Conservative Home Secretary Theresa May who claimed that the riots were about "sheer criminality" . Despite this, a range of explanations that can be viewed as broadly 'social' such as problems with 'the underclass ${ }^{9}$, race $^{10}$, poverty ${ }^{11}$, and the role of social media ${ }^{12}$ have also been proposed as 'causes' for the riots in the media. The role of the Police was also considered, with attention focussing on the way the Police dealt with the riots ${ }^{13}$, including suggestions that they did not act harshly enough ${ }^{14}$, public anger towards the Police ${ }^{15}$ and also the justice system more broadly ${ }^{16}$. Finally, the initial shooting of Mark Duggan, was also considered $^{17}$, although this was given less attention than many other explanations.

\section{'Traditional' Social Psychological Explanations of Riots}

What is striking about the explanations that were suggested in the media is the lack of reference to social psychological explanations of rioting and crowd behaviour, despite its long history of investigating precisely this. The earliest, and most enduring, explanation for crowd behaviour comes from Le Bon (1895/1947) who argued that the act of being part of a crowd created a sense of anonymity for its members, thus causing a loss of personal responsibility and unpredictable behaviour to spread through contagion. Le Bon states that 'by the mere fact that he forms part of an organised crowd, a man descends several rungs in the ladder of civilisation. Isolated, he may be a cultivated individual; in a crowd he is a barbarian - that is, a creature acting by instinct' (1895/1947, p. 13).

Additional theories which view crowds as especially problematic came from McDougal (1920) who viewed crowds as 'primitive' and Freud (1921) who claimed that being in crowds unlocked the unconscious. Similarly, Allport (1924) suggested that being in crowds allows individuals to ignore their socialisation which exacerbates their primitive needs. These theories, which highlight the loss of individual identity when in crowds led to the notion of 'deindividuation', as introduced by Festinger, Pepitone and Newcomb (1952) and developed by Zimbardo (1970). According to this theory, when people become anonymous they may lose their sense of self and their inhibitions, and with it their sense of right and wrong. This can happen in a crowd, which may cause people who are otherwise moral, to act badly. It has been demonstrated that modern policing strategies regarding riots and crowds, particularly those involving the control of them through force, are largely based on this traditional approach (Hoggett \& Stott, 2010; Stott, Adang, Livingstone \& Schreiber, 2008).

While the lay explanations described above do not appear to be based in this traditional social psychological literature on crowd behaviour, they do share some similarities with this traditional approach. In particular the notion of opportunism, where rioters were viewed as capitalising on the situation for their own personal greed draws on the idea that people do negative things in crowd situations that they would not otherwise do. In addition, the explanations regarding moral decline and problematic youth culture share similarities with the explanations of crowds bringing about primitive and atavistic behaviour (although in these explanations for the England riots this primitivism is largely presented as already being in place and exacerbated by the crowds, rather than caused by it). Arguments that the Police did not act forcefully enough to prevent the riots also draw on the traditional explanation of crowds, as according to the approach, the excesses of crowd behaviour needs to be strongly combated (see for example Hoggett \& Stott, 2010).

\section{Elaborated Social Identity Model (ESIM) of Crowd Behaviour}

Despite the traditional theories of crowds' continuing influence on Police strategy for dealing with crowds, and to a lesser extent, public discourse about riots, their approach has come under serious academic criticism, to the extent that it can no longer be considered the dominant explanation of crowd behaviour in social psychology (e.g. Hoggett \& Stott, 2010). The theory that has developed as part of the critique of the 
traditional approach to crowds is the 'Elaborated Social Identity Model (ESIM) of crowd behaviour' (e.g. Reicher, 2001). Specifically, Reicher (1984; 1987; 1996a) argues that authors such as Le Bon were politically motivated to present crowds (who were demanding equal rights) in a negative light. Therefore, rather than attempting to properly understand them, authors such as Le Bon were more interested in how to control them. Reicher suggests that these traditional approaches succeed in 'removing crowd action from its social context' (1996a, p. 115) and view only 'sovereign individual identity' (1984, p. 2) as a legitimate and rationale type of identity (as can be seen in the notion of deindividuation).

Instead, throughout a range of qualitative and quantitative empirical research studies (see Drury \& Reicher, 1999; Reicher, 1996a, 1996b; Reicher et al., 2004; Stott \& Drury, 2000; Stott \& Reicher, 1998), ESIM has drawn upon Social Identity theory (e.g. Tajfel, 1982) and Self Categorisation theory (e.g. Turner et al., 1987) to suggest that individual members of a crowd do not lose their sense of self (i.e. deindividuation) but instead move to the level of group identity (a process called 'depersonalisation') where individuals aim to act in a manner that is normal (or prototypical) of that group; this therefore leads to conformity to group norms which allows (rather than causes) individuals to behave in the same way as other group members. An example of this would be that in a demonstration against public sector pay freezes, members of the crowd would all identify as public sector workers and, perhaps, opponents of the government. So from this perspective, identity is not lost in a crowd, but instead a particular identity becomes especially relevant. Members of crowds are therefore not viewed as irrational, but as rational people sharing a social identity, often for a political purpose, such as opposing controversial taxes (e.g. Stott \& Drury, 2000). Reicher's (1984) analysis of the 'St Pauls riots ${ }^{18}$ demonstrated that violence was targeted in line with the aims of the group (rather than spreading in a disorganised or random manner), the riot stayed within the relevant area for the group (they did not leave the St Pauls area) and that members of the crowd reported high levels of group identity. Stott and Drury (2000) analysed the British 'poll tax ${ }^{19}$ riots and demonstrated a common feature of ESIM, that the violence erupted and spread as a result of differing perceptions of what is (or is not) legitimate action and the behaviour of the 'out group':

Crowd members defined the action of the 'violent' or 'disruptive' minority as nonthreatening or irrelevant. The police defined it as dangerous, and acted ... by intervening against the crowd as a whole .... [this] created a struggle over the physical occupation of space which [changed] ... their social relations... those in the crowd who engaged in 'violence' against the police became prototypical for large sections of the crowd (Stott \& Drury, 2000, p. 267)

What this means is that the widespread violence only became possible because the actions of the Police were perceived as an attack not just on a violent minority but the crowd as a whole. Compelling evidence for ESIM comes from the application of the theory. Stott and Reicher (1998) argued that the best solution to football hooliganism and group violence and disorder at a more general level, was to have Police address individual trouble makers in order to minimise the group feeling that they are being punished unfairly. Stott et al. (2007) worked with Portuguese Police during the 'Euro 2004' football tournament in an attempt to minimise English football hooliganism. They pointed to the ESIM finding that groups generally police themselves, and that violence is likely to depend on the perceived legitimacy of the actions of the outgroup (in this case the Portuguese Police) and so recommended the specific targeting of 'troublemakers' rather than English football fans as a whole. They found that in this particular case this strategy prevented rioting altogether.

\section{ESIM and the England Riots}

While ESIM may arguably be the dominant explanation of riots in social psychology, and one that the Police are beginning to adopt (Reicher et al., 2004) this type of explanation doesn't appear to figure in the explanations for the England riots. However, some of the references to the 'underclass', race and poverty and 
some anger towards the Police could share some of the underpinning principals of ESIM, particularly the suggestions that demonstrations are a form of social action (e.g. Reicher, 1987). That the shooting of Mark Duggan was also discussed seems the most relevant to ESIM, although as was noted, this explanation was given a disproportionately small amount of consideration. While ESIM does appear to offer a good critique of the traditional theories of crowd behaviour and provides evidence of being a better explanation for it, ESIM may struggle to explain why the England riots became so widespread so quickly and why (unlike in the St Pauls riots, for example) the violence didn't seem to be directed at a specific target.

Reicher and Stott (2011) responded quickly to the England riots and drew on their background in ESIM and crowd psychology to offer what they describe as a provisional reaction to the riots. They criticise the media and political responses to the riots for, as this review has illustrated, tending to reflect the 'traditional' and outdated understanding of riots that draws on the notion of 'mobs', 'deindividuation' and lax policing. However, they state that 'we cannot be confident that 2011 is different from all the other occasions in history where riots have been dismissed as criminal, but the reality has proved to be far more complex' (Reicher \& Stott, 2011, Kindle Locations 561-562). They argue against the commonly given explanations that suggest that (1) rioters do not belong to the community where the riots occur, (2) riots (and rioters) are mindless and disorganised and (3) that agitators influence riots and rioters (2011, p. 660-663). Parallels are made with previous riots that were also originally viewed as mindless and 'purely criminal' but afterwards shown to have been more organised events caused by social grievances. It has even been argued that information was misused to wrongly suggest that the traditional explanations of crowd behaviour could account for the England riots (Ball \& Drury, 2012).

Reicher and Stott (2011) describe the events that led up to the riots and point not to the actual shooting of Mark Duggan, but the resulting protest outside Tottenham Police station as the 'catalyst' for the riots. They state that protestors were demanding an explanation of the circumstances of Duggan's death, which had not been given (possibly in part because of the Independent Police Complaints Commission (IPCC) intervention). Police and protestor accounts of what happened differ, with the Police saying that objects were thrown when protestors began to fear that they would not be given an explanation that day; conversely the protestors claim that riot Police came out of the station before any rioting began. Either way, they state that riot Police were present and shortly afterwards a woman (the majority of protestors were women) was pushed and struck to the ground. After this the riot in Tottenham began, although Reicher and Stott point out that these were not disorganised, or only about looting: 'violence was not random ... First, police targets ... bore the brunt of attacks. ... Secondly, those shops that were attacked, tended to be those owned by outsiders ... those owned by insiders were either left alone or actively defended. Lastly, where locals were endangered by the riot ... rioters acted to safeguard them' (2011, Kindle Locations 1177-1181). The riots that followed in Ealing and Croydon are given less attention, but are described as being not about the Police, and rather about class as supposedly 'rich' people and their property were targeted. The riots that spread around England are described as assertions of power. Reicher and Stott conclude by stating that 'Grievance, lack of opportunity, shared identity and empowerment emerge as four key concepts to understanding the events of 2011' (2011, Kindle Locations 1473-1474).

\section{Early Literature on the England Riots}

Reicher and Stott, however, are not alone in responding quickly to the riots. Literature on the riots is already growing. Like Reicher and Stott (2011), Bridges (2012) agrees with the following points (1) the confusion surrounding the shooting of Mark Duggan, and the following lack of communication, acted as the catalyst for the riots, (2) there were clear similarities with previous riots, (3) the early riots were clearly directed as anti-Police action, (4) there were underlying social problems that contributed to the riots, (5) there was more to the riots than simply 'pure criminality' and (6) the policies set up to deal with the riots have misunderstood (or, perhaps, intentionally avoided) the genuine causes of the riots and so are destined to 
failure. Gorringe and Rosie (2011) also criticise the notion of the crowd as 'mad', pointing to policing strategies as important to the development (or not) of riots, and agree that the riots were about much more than simply crime. They offer three connected causes for the riots 'disaffection with economic prospects; serious levels of mistrust between young people and police; and a realisation that when faced with large and mobile numbers of rioters, the police are often powerless to stop looting and arson' (2011, p. 19). Klein (2012) also argues that problems with policing strategies may have contributed to the escalation of violence in the riots. Interviews with some of the rioters themselves (Roberts, 2011 ${ }^{20}$ ) identified a number of causes for the riots, including frustration with the way they are treated by, and a lack of respect from, the Police as well as the shooting of Mark Duggan (including those outside of London). Opportunism was also identified as a cause. Rioters were predominantly found to be from deprived areas. Other motivations expressed included economic injustice, the increase in student fees and the ending of 'educational maintenance allowance $^{21}$ (almost half of the participants were students) and the closing of youth services.

\section{Rationale and Aims}

It can be seen that the explanations that were offered in the media for the England riots share far more in common with the traditional, and recently criticised, approaches to understanding crowds and riots. The media and political responses therefore ignored current literature. However, while attention has been given to these media and political responses, literature searches reveal no academic attempts to engage with the general public to ascertain their opinions and explanation of the riots ${ }^{22}$. Reicher and Potter (1985) did assess lay accounts of the St Pauls riots, identifying errors in the accounts and similarities with the traditional explanation of crowds. However, the St Pauls riots are now largely forgotten in history and were not a national event with the same impact of the 2011 England riots. Therefore, it is important to get a picture of how the general public view the riots in order to gain a fuller understanding of the riots and their impact on society. Public opinion may also play its part in influencing government policy. To fill this gap in the literature and in the public understanding and reaction to the England riots, the aim of this study is find out what members of the public have to say about the riots.

\section{Method}

\section{Participants}

A total of 18 participants took part in four focus groups, consisting of three to five participants per group, in early 2012. Participants were all students at a West Midlands university, where they were recruited. Participants were predominantly female, mirroring the demographics of the courses they were recruited from. While this may suggest a limited demographic population, students were drawn from different courses (including under-graduate and post-graduate students) and therefore represent a demographically diverse group. Ages ranged from 18 to 37 years.

\section{Procedure}

This study is part of an ongoing project into the public understanding of the riots drawing on a range of psychological disciplines and methodological approaches. As this is the initial stage of the study and is exploratory, it was decided that focus groups would be conducted to gain qualitative data for thematic analysis. Focus groups are ideal for generating interaction between participants, making them an ideal forum for discussions to talk place (Puchta \& Potter, 2004). Four focus groups were conducted as these provided ample data for analysis, constituting approximately three hours of data. Thematic analysis was deemed the most appropriate method for generating good descriptions that summarise and identify key elements of qualitative data (Braun \& Clarke, 2006); this is therefore an ideal method for the initial exploratory stage of the research project that can provide a suitably detailed overview of the ways in which participants make sense of the riots. 
Focus groups were conducted by the first and third authors. The interview schedule was semi structured so questions were open ended to allow for participants to fully express themselves. Examples of questions included 'What do you think may have caused the riots?' and 'What could be done to stop similar events from happening in future?'. A second set of questions were designed to ask participants their opinions about a range of explanations that were included in the media (including those described above). This section began 'It has been suggested that a number of factors are responsible for causing the riots, what do you think about...' followed by one of the media or politician's explanation such as 'family breakdown'. These questions were asked at the end to attempt to remove any possible researcher influence on earlier answers. Focus groups lasted approximately one hour each.

\section{Analysis}

Data was transcribed verbatim by the third author and was analysed according to the steps set out by Braun and Clarke (2006), which meant that all authors coded the data, searched for themes based on these codes, reviewed the themes as a team and finally defined themes. Data was analysed at a broadly semantic level, so accounts were taken at face value rather than making assumptions about what participants may 'really' be thinking or about what they are doing with their talk. This decision was made because this part of the study is the first, exploratory part of an ongoing project. The analysis was conducted both inductively and deductively, although the emphasis was on the inductive aspect. As this stage of the research project is exploratory it followed that the analysis would be primarily inductive and this was reflected in the questions that dominated the interview schedule which were designed to elicit general opinions about the riots. However, as participants' responses to the explanations offered publically in the media were also to be addressed, a deductive element was required to assess this. While participants discussed and offered a range of explanations for the riots it is noteworthy that when participants were asked about specific causes of the riots that had been discussed in the media and/or by politicians (the questions designed for deductive analysis) responses followed a similar pattern. Participants tended to respond by dismissing these suggestions as overly simplistic and not as credible explanations, to the point that none of the explanations that were covered warrant discussion here. This means that the analysis presented here focuses only on the inductive part of the analysis. Validity (see Yardley, 2008) was ensured by getting all authors to co-analyse and agree on themes and by gaining respondent validation.

\section{Results}

The analysis resulted in a range of themes which are presented in Table 1. Each of these will now be addressed in turn. Extracts presented are chosen as exemplars of the theme being presented.

\section{Theme One: Traditional' Explanations for Riots}

It can be seen in the analysis that the ideas from the classic theories on crowds are predominantly offered up as explanations for the riots. For example, from Le Bon's (1895/1947) theory the idea of anonymity and contagion are commonly used to account for the riots. The notion of a mob was only referred to by one participant and suggestibility was not offered as an explanation at all. Each of Le Bon's explanations that were mentioned will be addressed in turn.

Anonymity and deindividuation. The idea that people in the riots behaved as they did because they were anonymous and therefore able to act in a way that they would not normally, appeared in all but one of the focus groups. Participant five states that 'there's anonymity in it though, wasn't there' (P5, FG2, 283). Participant one goes into more detail about this 'when you've got thousands of people running round it's more difficult to catch you for doing something wrong because you're sort of part of that crowd and people kind of lose their identity' (P1, FG1, 132-136). 
Table 1. Themes with illustrative extracts.

\begin{tabular}{|c|c|c|}
\hline Theme & Sub Theme & Illustrative extract \\
\hline $\begin{array}{l}\text { 1. Traditional } \\
\text { theories of the } \\
\text { crowd }\end{array}$ & $\begin{array}{l}\text { 3. Anonymity } \\
\text { and contagion } \\
\text { 4. Crowds as a } \\
\text { Mob }\end{array}$ & $\begin{array}{l}\text { it's more difficult to catch you for doing something } \\
\text { wrong because you're sort of part of that crowd and } \\
\text { people kind of lose their identity } \\
\text { I remember feeling, as it, as the news was progressing } \\
\text { day by day, and it was like this contagion effect, and then } \\
\text { it started happening in Birmingham } \\
\text { it's like everyone's inhibitions were just reducing and } \\
\text { people were just doing what they wanted and it's like this } \\
\text { contagion's happening } \\
\text { they crowded round to look like they were helping him } \\
\text { when actually they were kicking his head in and robbing } \\
\text { him and it's like, ok, yes as a mob }\end{array}$ \\
\hline 2. Police can't win & - & Damned if they don't, damned if they do \\
\hline 3. Opportunism & - & $\begin{array}{l}\text { They sort of saw an opportunity to take what wasn't } \\
\text { theirs }\end{array}$ \\
\hline $\begin{array}{l}\text { 4. The role of the } \\
\text { media }\end{array}$ & $\begin{array}{l}\text { 1. Facilitating } \\
\text { the spread of the } \\
\text { riot } \\
\text { 2. Informing } \\
\text { people } \\
\text { 3. Facilitating } \\
\text { the clean up }\end{array}$ & $\begin{array}{l}\text { It's just the speed at which these things spread, due to all } \\
\text { the things we've said - the media, social networking } \\
\text { I heard about it on the BBC news } \\
\text { It also played a part in showing people doing the cleanup }\end{array}$ \\
\hline $\begin{array}{l}\text { 5. Understandable } \\
\text { not acceptable }\end{array}$ & - & $\begin{array}{l}\text { The motives behind them I can understand but as an } \\
\text { action it's just no way can that be acceptable }\end{array}$ \\
\hline
\end{tabular}

Here the idea is that anonymity allows people to think that they are more likely to get away with a crime, but the process of deindividuation makes members of the crowd lose their individual identity. This means that they are less likely to think about the appropriate behaviour, which suggests that as well as being less likely to get caught, members of crowds are more likely to engage in behaviour which they may get in trouble for doing. Participant nine gave a similar account by stating that 'people just thinking they can just, you can do this' (P9, FG2, 103-105) which again suggests that there is something about being in a crowd that allows people to feel that they can get away with what they normally would not consider, something that is attributed to the lack of consequences 'because there didn't seem to be any real consequences potentially to those people' (P7, FG2, 115-116).

Contagion. The next of Le Bon's explanations for group behaviour, contagion, was also referred to regularly by a range of participants. Here it was suggested that the rioting behaviour spread throughout those in the group. Clear examples of this can be seen in the following "I remember feeling, as it, as the news was progressing day by day, and it was like this contagion effect, and then it started happening in Birmingham" (P6, FG2, 36-38) and "it was just happening and people were just getting whipped up and brought into it" (P18, FG4, 180-181). In two focus groups participants collectively drew on the notion of contagion, as can be seen in the following extracts:

P3 so it obviously is a social thing that is catching on

Int. Ok

P2 It's like jumping on the bandwagon (FG1, 151-153) 
P11 Y'know, one person does it so another does and then others follow, I don't know there's elements of that involved

P10 Mmm

Int. Kind of a contagion?

P10 Yeah

P12 Mmm

P11 Yeah (FG3, 107-113)

It can therefore be seen that not only was contagion often offered as an explanation for the rioters' behaviour, but that there was agreement amongst the participants that this was the case.

Anonymity and contagion. While there were a number of separate references to anonymity (including deindividuation) and contagion these two concepts were also brought together so that a relationship between them was presented. In the following case deindividuation (and resulting lack of inhibitions) was used to account for the contagion "it's like everyone's inhibitions were just reducing and people were just doing what they wanted and it's like this contagion's happening and it's spreading out across the country" (P6, FG2, 46-47). However in the following extracts the reverse happened and contagion was used to account for the deindividuation: "people maybe noticing that so many other people were involved in the riots that there was this kind of contagion, this idea of maybe collective irresponsibility whereby y'know, because there's loads of other people rioting then I won't get caught if I do this" (P8, FG2, 134-137) and "I agree with what you were saying really about kind ... going viral really and then people just thinking they can just, you can do this" (P9, FG2, 103-105).

Crowds as a mob. The idea that members of the crowds in the riots were acting as a mob was rare in the data, but was mentioned in two focus groups. In this first extract the term mob is explicitly used "they crowded round to look like they were helping him when actually they were kicking his head in and robbing him and it's like, ok, yes as a mob" (P3, FG1, 101-102) and in this next example the same participant makes a similar point, however this time rather than referring to a mob, the notion that members of a crowd lose their civilised nature is stated instead: "Ultimately when there is something to fight over, people do, well, degenerate for want of a better word, into just scrapping basically" (P3, FG1, 177-178). In this final extract the notion of contagion was drawn upon to present the situation as mad, which again draws on the idea that crowds act in an irrational and disorganised way. "I was like, getting quite frightened really "cause it was happening all over the country thinking, it'll be [Name of city] next or, y'know. It could, y'know, it's like the world was going mad" (P6, FG2, 40-42). This section has shown that, although less common than the notions of contagion and anonymity, the idea that crowds can be seen as a mob can be found in these explanations.

\section{Theme Two: The Police, Damned if they do; Damned if they don't}

All of the focus groups made some mention of the Police being 'damned if they do, damned if they don't'. Two focus groups had the perception that the Police, and how they were able to deal with or manage the riots, were caught in a helpless no win situation. This is evident in the following two examples:

P15 I don't know, I think maybe seeing it from their kind of point of view, I think also a lot of things feel quite hopeless from a lot of Police officers

P16 Damned if they don't, damned if they do". (FG4, 652-655)

P10 I think the Police were in a no win situation. If they'd gone in hard they'd have been criticised, if they don't do anything at all they'd have been criticised...

[Three lines omitted] 
P13 They have been, sort of, criticised for not going in hard enough weren't they? [Eight lines omitted]

P12 It's a no win situation. (FG3, 444-458)

Further support for this theme, comes from the beliefs that the media portrayed the Police in a manner that left them criticized for any actions that were taken (or actions not taken). For example, one participant noted "but y'know, like you say, if they don't do anything they get criticized, and if they do something then they get heavily criticized as well" (P1, FG1, 584-586). In another example, the Police were seen again as unfairly treated for the way that they were portrayed by the media.

P8 I don't really know about the incident, regarding the Police, I feel the Police got an unfair, unfairly bad press

Int $\quad$ Ok

P8 About the riots, I felt there was, the way the media handled it, it seemed like there was no way the Police could win, they would be criticized for being too heavy handed

P9 No, I agree (FG2, 748-754)

Therefore, although the Police were seen as not necessarily doing the right things, the views were that this would have been the case no matter what actions had been taken.

\section{Theme Three: Opportunism}

The idea that the rioters were acting in an opportunistic way, that is taking advantage of the situation and taking what they could for personal gain, was a predominant feature of the data. Examples of participants referring directly to opportunism can be seen with participants stating that "there must've been an element of opportunist" (P7, FG2, 73) and that it was "Quite opportunistic" (P10, FG3, 55). One participant elaborated by saying "so the original political case was nothing to do with these people they were just doing it "cause there was opportunity to do something" (P18, FG4, 228-230) so here a political motivation is recognised, but instead many of the rioters are considered to be acting out of opportunism only. Other participants went a step further and suggested that the opportunity available related to consumption and stealing, examples of this include "They sort of saw an opportunity to take what wasn't theirs" (P2, FG1, 109), "I think in some ways, people, some people saw an opportunity to nick something" (P9, FG2, 920) and speaking as those involved " 'y'know I'm gonna go off to this electrical store, help myself let's just, y'know, let's just try and get as much stuff for free as we can'. I, I think there was an element of that in it" (P11, FG3, 88-90). These examples therefore show that participants do consider opportunism, and in particular the opportunity to steal, to explain why some of the rioters rioted.

\section{Theme Four: The Role of the Media}

Throughout the focus groups the role of media, both traditional media (newspapers and television news) and new 'social media' (such as the use of text messages, Facebook and Twitter), were the focus of much attention. However, talk about the media tended to be ambivalent, with both support and criticism being displayed. This ambivalence is illustrated in the range of subthemes for media, (1) facilitating the spread of the riots, (2) informing people and (3) facilitating the clean up. These will each be addressed in turn.

Media and spread of the riots. In this section it can be seen how the media is presented as in some way culpable for helping to spread the riots. Examples of this from one participant are "the media probably has a lot to answer for I suppose, it was just rolling on and on and on and on" (P15, FG4, 454-455) and "Imagine if there was no media though? It just would've fizzled out in a day" (P15, FG4, 919) and from another participant "It's just the speed at which these things spread, due to all the things we've said - the media, social networking, and so on and so forth" (P3, FG1, 477-478). In this next extract the media are 
blamed for highlighting weakness in the Police which was seen as exacerbating the riots "I felt like in the media, I'm thinking stop telling everyone the Police can't handle it because it's just fuelling the rioters, giving them more confidence" (P5, FG2, 758-763), a point that received agreement from other participants in that focus group. In this next exchange, shortly after the previous comment, participants in the focus group can be seen to agree on the damaging nature of the media:

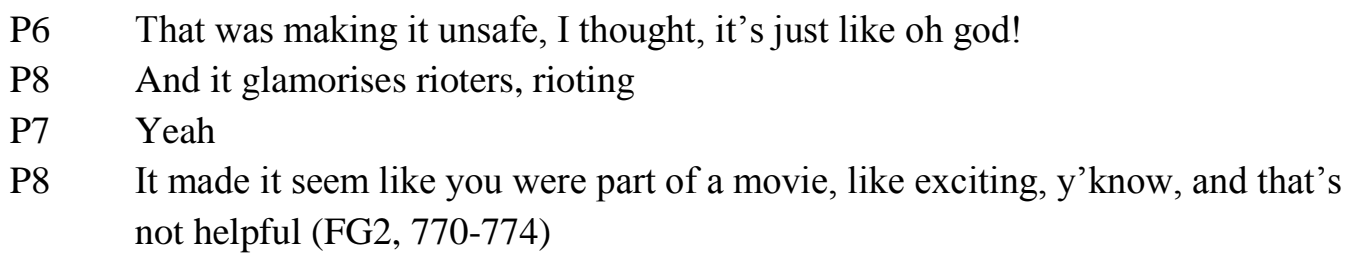

It can therefore be seen that the media was held to be partially responsible for helping to spread the riots through informing potential rioters, suggesting that the Police were out of control and presenting the riots as glamorous which may have sparked interest in others.

Informing people. However, the input of the media was also welcomed as it is credited with informing the public about the riots. Most participants stated that they had first heard about the riots because of traditional media, so for example "I think I heard about it on BBC news, urm, y'know, it was on the radios as well so it was kind of all over the media" (P11, F3, 11-12) and "I remember it came in and at first I don't think I understood exactly what was going on. Then I remembered the news, like, and related the events together." (P4, F1, 77-78). Other participants found non traditional media, including social media to have been informative "I just noticed feeds coming up on Facebook" (P15, F4, 8) and "the way that Facebook is, all it took was a quick log in to Facebook and there was like a frenzy" (P18, FG4, 92-93). In this way both traditional and 'social' media is seen as having the more positive role of keeping the public informed.

Facilitating the clean up. Finally, the media was also presented in another positive way, as facilitating the clean up that followed the riots and also helping to ensure calm in the public afterwards. In this first example the media focus on the clean up after the riots is seen as redeeming the media for its helping to facilitate the initial spread of the riots "in the papers a lot of people actually in cities gathering together as groups and like saying clean up our streets. So ... the media portrayed us as a country that sort of came back together to sort it all out and y'know, whilst obviously it would've done a lot of damage, the media, it also would've done a lot of repairs in that respect" (P3, FG1, 323-331) and in another example "but it also played its part in showing people doing the cleanup and the, y'know, group community feel and that might have helped to calm things later on so" (P12, FG3, 676-678). Social media was also presented as a positive method for helping to counter the riots "Well people on my Facebook were sort of getting together to protect our local town" (P2, FG1, 342).

Overall, therefore the role of the media is presented as complicated; it is blamed for helping to spread the riots initially, but it is also credited with informing people and helping to improve the situation in the immediate aftermath.

\section{Theme Five: The Riots were Understandable but not Acceptable}

This theme relates to the way in which participants responded to a question about whether or not they thought that the riots were in any way acceptable. Many participants responded that while there may be understandable causes, that the actions themselves were not acceptable. These responses were all similar, making a distinction between what is understandable and what is acceptable, for example "initially the motives behind them I can understand but as an action it's just no way can that be acceptable" (P3, FG1, 605-606) and in this exchange two participants can be seen to be agreeing over this point: 
P7 if they're not given the opportunity to be able to be heard then it's understandable maybe, rather than acceptable

P5 Yeah, so that's the difference there isn't there. Acceptable versus understandable (FG2, 450452)

Finally, in this last extract we can see how most participants share this view, although there is some disagreement.

\author{
P15 Understandable, not acceptable \\ P18 I don't think understandable \\ P14 I think the feelings generated were understandable, I think the actions were \\ thoroughly unacceptable \\ P16 Mmm I would agree with that (FG4, 428-432)
}

It can therefore be seen that there is agreement as to why the riots may have occurred, but that the riots themselves remain heavily criticised. While this appears to be a dominant viewpoint, it is not however shared by all participants.

\title{
Discussion
}

This analysis has identified a number of themes from the participants' talk about the riots. The first theme shows how participants draw on ideas associated with the traditional theories of the crowd (and in particular Le Bon, 1895/1947) so that rioters were presented as acting the way they did because they were anonymous within the crowd of rioters and so were in a state of 'deindividuation' (e.g. Zimbardo, 1970) and that because of the nature of crowds this deindividuation was contagious. The second theme focussed on the way in which the Police were talked about sympathetically because they are deemed to come under criticism no matter what they do. The third theme addressed the way in which opportunism was used to account for much of the looting; that is rioters were seen as taking advantage of the situation and using it as an opportunity for personal gain through stealing where they thought they would not be caught. The fourth theme focussed on the sometimes ambivalent talk about the media. The media was viewed as aiding the spread of the riots, through pointing out weaknesses in the Police and presenting the riots as exciting, but also as informative and as aiding the cleanup operation and a restoration of communities after the riots ended. Finally it was shown that participants responded to questions about whether or not the riots were acceptable by saying that while they may be understandable, they were in no way acceptable.

The first theme is particularly noteworthy because while the 'traditional' theories of crowd behaviour have been largely replaced by the ESIM approach to crowds, the accounts of the participants share many similarities with the traditional approaches, and very little with that of the ESIM. All of the major tenets of the traditional approaches are present in the data, with deindividuation (e.g. Zimbardo, 1970), contagion (Le Bon 1895/1947), and 'mob mentality' (Le Bon 1895/1947) all being mentioned. This is perhaps unsurprising given the prominence that these explanations were given in the media. Nevertheless this demonstrates that while the traditional approaches may have come to be viewed as outdated within social psychology (e.g. Hoggett \& Stott, 2010) this does not seem to be the case within members of the public, which suggests that there is a major lag between the literature and public understanding. This appears to point to the need for crowd psychologists to be given a more prominent platform in public debates about events such as the England riots and also points to the contribution that psychologists can make in dealing with social issues more widely.

The second theme relates to the Police and demonstrates more sympathy than may have been expected for the Police given the criticism that they came under following the riots. The participants responded to the situation where the Police will be criticised for not acting harshly enough (as seen in the media explanations presented above) but that they can also become criticised if they act in a way deemed to be too harsh. As the 
traditional approaches to crowds have been shown to inform how the Police have come to deal with crowds (e.g. Reicher, 1987) it would follow that the Police would be expected to act harshly and would be criticised for 'allowing' riots to occur. This, therefore, suggests that the participants do have a more sophisticated understanding of the role of Police in the riots than simply suggesting that they should always be as harsh as possible, as the traditional approaches to crowd control would imply.

From an ESIM point of view, the Police are not doomed to criticism whatever they do; there is evidence to suggest that if the Police are allowed to adopt a strategy more in line with the ESIM, then they can be extremely effective in preventing riots in the first place (e.g. Stott et al., 2007). Certainly working with the Police, rather than blaming them, should help to improve the chances of preventing future riots (Reicher et al., 2004). A practical application for this finding therefore would be to allow the Police to continue to adopt ESIM strategies for better policing crowds, and resisting any call for the Police to engage in more confrontational tactics of the sort that have been shown to only make the problem worse (e.g. Klein, 2012).

The theme on opportunism links in with the first theme on the traditional approaches to crowds, as this does hint at contagion and a return to 'primitive' ways of acting based on atavistic needs (in this case to gain possessions) when people are in crowds. Accounting for part of the riots with opportunism does align with Roberts' (2011) findings. That participants said there may have been looting that was unconnected from the main riot is interesting, as it may imply that those who weren't acting opportunistically may have been doing more than simply getting swept up in the riot; that is that they may have had some purpose. If this is the case then it suggests a departure from the traditional explanations of riots as displayed in the first theme.

The fourth theme relates to the role of the media that was seen as having a mixed effect, both helping to (inadvertently) spread the riots as well as glamorising them, but also helping to inform the public and to aid the more positive elements that followed the riots. It is noteworthy that participants tended not to make much distinction between traditional and 'social' media, although traditional media was presented as more trustworthy, while also coming under the most criticism. Practical applications from this theme therefore could be that the media could report issues in a more measured way, rather than helping to create a sense of excitement during troubling news events.

The final theme demonstrates how participants, unsurprisingly, consider the riots to have been unacceptable, but more interestingly that they do consider them to be understandable. What this means is that while drawing heavily on the traditional approach to crowds and riots (as seen in theme one) participants also suggest that there may be underlying issues that caused the riots in the first place. This is an important finding as it demonstrates that opinions about the riots are more complex than they may have first appeared. This shows that, in line with ESIM, participants agree that there may be justification for unrest amongst the rioters, who are therefore seen as having legitimate concerns, and therefore cannot simply be part of a 'mob'. The practical applications here are substantial; on the basis of this it would seem that authorities need to address the underlying issues that are seen to have contributed to the riots (see Reicher \& Stott, 2001; Roberts, 2011).

\section{Further Research}

The paper reports the first part of an ongoing research project and is exploratory in nature, something that could be viewed as a limitation of the study. It is clear from these findings that more research needs to be conducted to gain a full understanding of the public's understanding of the riots. Some of these suggestions will be outlined here. First, a more in depth understanding of the issues encountered in this analysis needs to be gained, so more detailed analysis is required of what members of the public have to say about the role of the media (which appears to be complex) and the issues that are considered to be part of the reason why the riots may have been understandable. Therefore, there is the need for a far more detailed analysis of the way in which participants make their arguments, and in particular how they deal with some of the possible 
dilemmas in the accounts, such as the ambivalent approach to the media, the complex role of the Police and the way in which the events can be presented as both justifiable but also so unacceptable.

There is also scope for a more detailed understanding of attitudes towards the Police, the media and other institutions involved in explanations of the riots. Therefore, a next logical step in the research could be to conduct research of a cross-disciplinary nature that offers other possible explanations for rioting behaviour. For example, combining social and forensic explanations to investigate the causes of the riots, and explore the nature of the relationship between support for rioting behaviour and self-reported attitudes and/or individual characteristics (such as aggression) could be beneficial in increasing our understanding of this phenomenon.

\section{Conclusion}

This research has highlighted some of the ways in which members of the public talk about and account for the England riots. The findings show how participants draw predominantly on the traditional, and arguably outdated, explanations for rioting which view riots as devoid of any meaning. There was, however some sense that there was more to the riots than this, as participants felt that there were legitimate grievances that could explain the riots, even though the riots were deemed to be unacceptable. The roles of the media and Police were shown to be viewed with ambivalence. A number of practical recommendations are suggested, including giving a platform to crowd psychologists, allowing the Police to follow the ESIM of crowd behaviour, that the media should play a more responsible role in reporting on major events and that underlying issues that have contributed to the riots should be addressed.

\section{Implications for Practice}

- Policy makers need to engage with the up to date psychological literature about riots as outdated literature appears to dominate public and media spheres.

- Police crowd control policies should be based upon the Elaborated social identity model (ESIM) of crowd behaviour.

- To prevent future riots it will be necessary to address the underlying issues that lead to mistrust of police and authority.

\footnotetext{
${ }^{1}$ See BBC bbc.co.uk/news/uk-10321233 for more details

${ }^{2}$ See, for example, CNN edition.cnn.com/2011/WORLD/europe/08/10/uk.riots.international.view for more details

${ }^{3}$ dailymail.co.uk/news/article-2057492/England-riots-2011-chance-young-people-free-stuff.html

4 guardian.co.uk/uk/2011/dec/05/morality-of-rioters-summer-riots?INTCMP=SRCH

5 This refers to the British television programme that Conservative work and pensions secretary blamed for promoting what he called a 'get rich quick' culture. See guardian.co.uk/uk/2011/dec/09/x-factor-culture-fuelled-riots

${ }^{6}$ Referring to corporal punishment being illegal in the UK. See dailymail.co.uk/news/article-2096641/Support-endsmacking-ban-parents-say-prevented-summer-riots.html

and dailymail.co.uk/news/article-2041855/Sir-Ian-Botham-Bring-cane-sort-Britains-yobs-prevent-riots.html

${ }^{7}$ dailymail.co.uk/debate/article-2067399/England-summer-riots-inquiry-Opportunism-simple-truth.html

${ }^{8}$ See bbc.co.uk/news/uk-politics-14449979

${ }^{9}$ This refers to very poor people, usually long term unemployed. See telegraph.co.uk/news/uknews/law-andorder/8630533/Riots-the-underclass-lashes-out.html

${ }^{10}$ blogs.telegraph.co.uk/news/katharinebirbalsingh/100099830/these-riots-were-about-race-why-ignore-the-fact/ with particularly controversial comments made by the historian David Starkey on a BBC news programme, available here bbc.co.uk/news/uk-14513517

${ }_{11}^{11}$ guardian.co.uk/news/datablog/2011/aug/16/riots-poverty-map-suspects?INTCMP=SRCH

12 bbc.co.uk/news/uk-politics-14931010

13 bbc.co.uk/news/uk-15940907

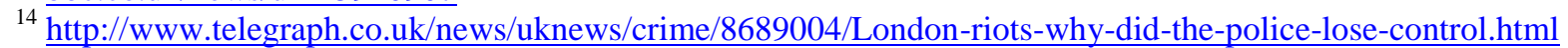

15 bbc.co.uk/news/uk-16018215

16 dailymail.co.uk/news/article-2034165/Broken-penal-caused-riots-claims-Kenneth-Clarke.html
} 
${ }_{17}^{17}$ guardian.co.uk/uk/2011/nov/28/england-riots-urgent-action-panel

${ }^{18} \mathrm{St}$ Pauls is a district of the English city of Bristol. These riots took place in 1980

${ }^{19}$ The poll tax was a particularly unpopular tax that was proposed for Britain. The riots occurred in London following a demonstration against this in 1990 .

${ }^{20}$ This report is available here: http://s3.documentcloud.org/documents/274239/reading-the-riots.pdf

${ }^{21}$ This was a small payment for A level students in low income families that was ended in England in 2011

${ }^{22}$ Although note the following report that dealt with victims' views http://webarchive.nationalarchives.gov.uk/20121003195935/http:/riotspanel.independent.gov.uk/wpcontent/uploads/2012/03/Riots-Panel-Final-Report1.pdf 


\section{References}

Allport, F. (1924). Social Psychology, Houghton Mifflin, Boston, MA.

Ball, R. \& Drury, J. (2012). 'Representing the riots: The (mis)use of statistics to sustain ideological explanation', Radical Statistics, vol. 106, pp 4-21.

Braun, V \& Clarke, V. (2006). Using thematic analysis in psychology, Qualitative Research in Psychology, 3, 77-10 DOI: 10.1191/1478088706qp063oa

Bridges, L (2012). Four days in August: the UK riots. Race \& Class, 54, 1, 1-12 DOI: $10.1177 / 0306396812446564$

Drury, J \& Reicher, S. (1999). The Intergroup Dynamics of Collective Empowerment: Substantiating the Social Identity Model of Crowd Behavior, Group Processes \& Intergroup Relations, 2, 381-402 DOI: $10.1177 / 1368430299024005$

Festinger, L., Pepitone, A., \& Newcomb, T.M. (1952). Some consequences of deindividuation in a group. Journal of Abnormal and Social Psychology, 47, 382-9 DOI: 10.1037/h0057906

Freud, S. (1921). Group Psychology and the Analysis of the Ego. (Translated from the German original Massenpsychologie und Ich-Analyse by James Strachey. Standard Edition, vol. XVIII, pp. 67-143. The Hogarth Press, London. 1981

Gorringe, H \& Rosie, M (2011). King Mob: Perceptions, Prescriptions and Presumptions About the Policing of England's Riots, Sociological Research Online, 16(4), 17 DOI: 10.5153/sro.2521

Hoggett, J. \& Stott, C. (2010). Crowd psychology, public order police training and the policing of football crowds. Policing, 33(2), 218-235. DOI: 10.1108/13639511011044858

Klein, A. (2012). Policing as a causal factor - A fresh view on riots and social unrest, Safer Communities, 11(1), 17 -23 DOI: $10.1108 / 17578041211200074$

Le Bon, G. (1947). The crowd: A study of the popular mind. London: Ernest Benn. (Original work published 1895)

McDougall, W (1920). The group mind: a sketch of the principles of collective psychology, with some attempt to apply them to the interpretation of national life and character. New York: G.P. Putnam's Sons

Puchta, C., \& Potter, J. (2004). Focus group practice. London: Sage.

Reicher, S. (1984). The St Pauls' riot: An explanation of the limits of crowd action in terms of a social identity model. European Journal of Social Psychology, 14, 1-21 DOI: 10.1002/ejsp.2420140102

Reicher, S. (1987). Crowd behaviour as social action In Turner, J C, Rediscovering the social group: a selfcategorization theory pp.171-202, Oxford, UK: Blackwell Publishers Ltd

Reicher, S. (1996a). 'The battle of Westminster': Developing the social identity model of crowd behaviour in order to explain the initiation and development of collective conflict. European Journal of Social Psychology, 26, 115-134: pp. 115 DOI: 10.1002/(SICI)1099-0992(199601)26:1<115::AIDEJSP740>3.0.CO;2-Z

Reicher, S. (1996b). The crowd century: reconciling theoretical failure with practical success. British Journal of Social Psychology, 35, 535-553

Reicher, S. (2001). The psychology of crowd dynamics. In M.A. Hogg and R.S. Tindale (Eds.), Blackwell handbook of social psychology: Group processes (pp. 182-208). Oxford: Blackwell

Reicher, S, \& Potter, J (1985). Psychological theory as intergroup perspective: A comparative analysis of 'scientific' and 'lay' accounts of crowd events. Human Relations, 38, 167-189.

Reicher, S., \& Stott, C. (2011). Mad mobs and Englishmen? London, UK: Constable \& Robinson

Reicher, S., Stott, C., Cronin, P., Adang, O. (2004) An integrated approach to crowd psychology and public order policing, Policing: An International Journal of Police Strategies \& Management, 27(4), 558-572 DOI: $10.1108 / 13639510410566271$

Roberts, D. (ed.) (2011) Reading the Riots: Investigating England's summer of disorder. London: Guardian books

Stott, C., Adang, O., Livingstone, A., \& Schreiber, M. (2007) Variability in the collective behaviour of England fans at Euro 2004: 'Hooliganism', public order policing and social change, European journal of Social Psychology, 37, 75-100 DOI: 10.1002/ejsp.338 
Stott, C., Adang, O., Livingstone, A., \& Schreiber, M. (2008). Tackling football hooliganism: A quantitative study of public order, policing and crowd psychology. Psychology, public policy, and law, 14(2), 115141. DOI: $10.1037 / \mathrm{a} 0013419$

Stott, C., \& Drury, J. (2000) Crowds, context and identity: Dynamic categorization processes in the 'poll tax riot'. Human Relations, 53(2), 247-273

Stott, C. \& Reicher, S. (1998) How Conflict Escalates: The Inter-Group Dynamics of Collective Football Crowd 'Violence'. Sociology, 32 353-377

Tajfel, H. (1982). Social identity and intergroup relations. Cambridge, England: Cambridge University Press

Turner, J., Hogg, M., Oakes, P., Reicher, S., \& Wetherell, M. (1987). Rediscovering the Social Group: A SelfCategorization Theory. New York: Basil Blackwell

Yardley, L. (2008). Demonstrating validity in qualitative psychology. In J.A. (Ed.), Qualitative psychology: A Practical guide to methods ( $2^{\text {nd }}$ ed.). London: Sage

Zimbardo, P. G. (1970). The human choice: Individuation, reason, and order versus deindividuation, impulse, and chaos. In W. J. Arnold \& D. Levine (Eds.), 1969 Nebraska Symposium on Motivation (pp. 237-307). Lincoln, NE: University of Nebraska Press. 